\title{
Efficient Light-Induced Phase Transitions in Halogen-Bonded Liquid Crystals
}

\author{
Francisco Fernandez-Palacio, ${ }^{\dagger, \nabla}$ Mikko Poutanen, ${ }^{\ddagger, \nabla}$ Marco Saccone, ${ }^{*}$, Antti Siiskonen, ${ }^{\S}$
} Giancarlo Terraneo, ${ }^{\dagger}$ Giuseppe Resnati, ${ }^{\dagger}$ Olli Ikkala, ${ }^{\dagger}$ Pierangelo Metrangolo, ${ }^{*}, \dagger, \downarrow, \perp$ and Arri Priimagi ${ }^{*}, \S$

${ }^{\dagger}$ Laboratory of Nanostructured Fluorinated Materials (NFMLab), Department of Chemistry, Materials, and Chemical Engineering "Giulio Natta”, Politecnico di Milano, Via L. Mancinelli 7, 20131 Milano, Italy

${ }^{\ddagger}$ HYBER Centre of Excellence, Department of Applied Physics, Aalto University, P.O. Box 15100, FI-02150, Espoo, Finland

${ }^{\S}$ Department of Chemistry and Bioengineering, Tampere University of Technology, P.O. Box 541, FI-33101 Tampere, Finland

${ }^{\perp}$ VTT-Technical Research Centre of Finland, Biologinkuja 7, 02150 Espoo, Finland

Supporting Information

\begin{abstract}
Here, we present a new family of light-responsive, fluorinated supramolecular liquid crystals (LCs) showing efficient and reversible light-induced LC-to-isotropic phase transitions. Our materials design is based on fluorinated azobenzenes, where the fluorination serves to strengthen the noncovalent interaction with bond-accepting stilbazole molecules, and increase the lifetime of the cis-form of the azobenzene units. The halogen-bonded LCs were characterized by means of X-ray diffraction, hot-stage polarized optical microscopy, and differential scanning calorimetry. Simultaneous analysis of light-induced changes in birefringence, absorption, and optical scattering allowed us to estimate that $<4 \%$ of the mesogenic units in the cis-form suffices to trigger the full LC-to-isotropic phase transition. We also report a light-induced and reversible crystal-to-isotropic phase transition, which has not been previously observed in supramolecular complexes. In addition to fundamental understanding of light-responsive supramolecular complexes, we foresee this study to be important in the development of bistable photonic devices and supramolecular actuators.

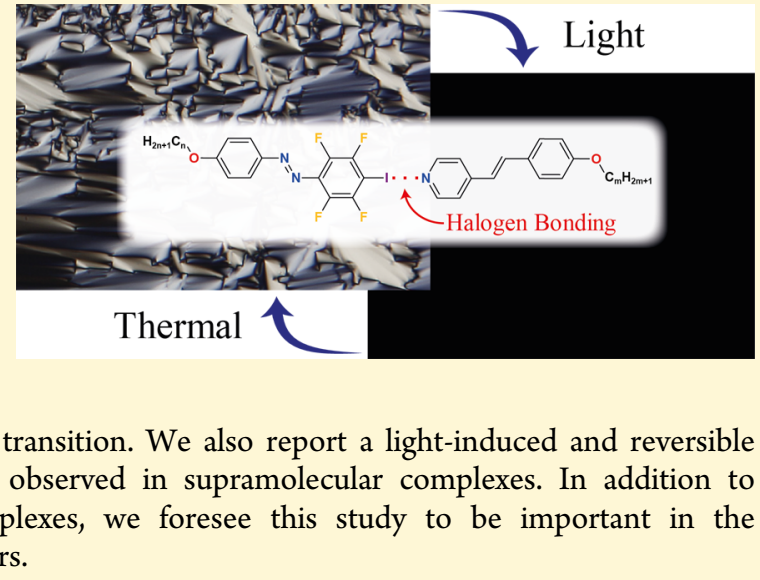

\section{INTRODUCTION}

Creating order and complexity through self-assembly of simple molecular building blocks is an important area of contemporary science. ${ }^{1,2}$ Yet, it is the external control over the molecular order that brings about technological disruptions, as well exemplified by the success of liquid crystals in display industry. Liquid crystals (LCs) constitute perhaps the best platform for exploring the interplay between self-assembly, molecular alignment, and stimuli-responsiveness, as they combine order and mobility in a unique way. ${ }^{3,4}$ As a remote, highly controllable energy source, light is a particularly attractive stimulus to control the LC phases. Through incorporation of light-responsive units into LC systems, several schemes for photomodulation of LC alignment have been devised, the main application potential lying in tunable photonics, functional surfaces, and light-to-mechanical energy conversion. ${ }^{5-8}$

Azobenzene unit is a particularly efficient molecular switch for controlling the molecular alignment in LC systems, because of its large and reversible shape change upon photoisomerization and the incompatibility of the bent cis-azobenzene configuration with calamitic mesophases. ${ }^{5}$ The focus of azobenzene-based LC research can be simplistically divided into two main directions. On one hand, there is a thrust to develop tunable materials whose properties (e.g., surface topography) can be rapidly and reversibly changed between the undisturbed and photomodulated states. ${ }^{9,10}$ On the other hand, several photonic applications would benefit from bistable photomodulation, ${ }^{11-13}$ i.e., temporally stable switching between two states, using distinct wavelengths that drive the reverse photoisomerization reactions. Various structures for bistable azobenzene photoswitches have been developed, ${ }^{14-17}$ and, among them, ortho-fluorinated azobenzenes appear particularly promising. ${ }^{14,15}$ Fluorination is also an effective strategy to tailor the anisotropy and viscoelastic properties of LCs, ${ }^{18,19}$ and boost intermolecular interactions for the selfassembly of supramolecular LCs. Combining these design principles, here, we target a new family of azobenzene-based, fluorinated supramolecular LCs with predictable phase behavior and efficient light-control over the molecular alignment.

In supramolecular LCs, specific noncovalent interactions drive the formation of supramolecular mesogens, even when starting from non-liquid-crystalline building blocks. ${ }^{20,21}$ They are pertinent from the viewpoint of increasing the modularity and tunability of conventional LC systems and obtaining

Received: August 22, 2016

Revised: October 5, 2016

Published: October 6, 2016 
functionalities not met in single-component or doped LCs. The majority of works in the field have concentrated on the design and structural characterization of supramolecular LCs. Their photochemical control, on the other hand, has not received much attention, whereas detailed studies have been conducted in single-component and doped LC systems. ${ }^{22-24}$ Understanding the dynamics of the light-induced processes, as well as the conditions under which photoinduced phase transitions occur in supramolecular systems, are not only fundamentally important, but also provide important design principles for supramolecular functional materials. Targeting photoresponsive, fluorinated supramolecular LCs, halogen bonding is the noncovalent interaction of choice.

Halogen bonding is an attractive interaction between an electrophilic region associated with a halogen atom in a molecular entity and a nucleophilic site. ${ }^{25}$ The benefits of halogen bonding, such as the high directionality and tunability, ${ }^{26-28}$ have recently been recognized in the design of functional materials. ${ }^{29,30}$ In particular, halogen-bonded, azobenzene-containing co-crystals ${ }^{31-33}$ and (amorphous) supramolecular side-chain polymers ${ }^{34,35}$ have shown extremely interesting photoresponsive properties, even superior to their hydrogen-bonded counterparts. Since the first demonstration in $2004,{ }^{36}$ several halogen-bonded LCs have been reported. ${ }^{37-41}$ Photoresponsive halogen-bonded LC complexes were first reported by some of us in 2012,,$^{42}$ and, in 2014, Yu et al. demonstrated photoinduced phase transitions in complexes between azopyridines and molecular halogens. ${ }^{43}$ However, neither of these studies detailed the photochemistry of the halogen-bonded LCs, which is crucial in terms of understanding their potential use in, e.g., supramolecular photonic devices and photoactuators.

Herein, we bridge this gap and report a detailed study on a small library of neutral halogen-bonded LCs, whose LC-toisotropic phase transitions can be efficiently controlled with light. We show that $<4 \%$ of the mesogenic units in the bent cisconfiguration suffice to induce a complete order-to-disorder transition of the materials. We also report a light-induced and reversible crystal-to-isotropic phase transition, which has not been previously observed in supramolecular complexes.

\section{RESULTS AND DISCUSSION}

The materials used in this work are shown in Figure 1. We assembled 15 dimeric co-crystals 1-m.2-n in which the

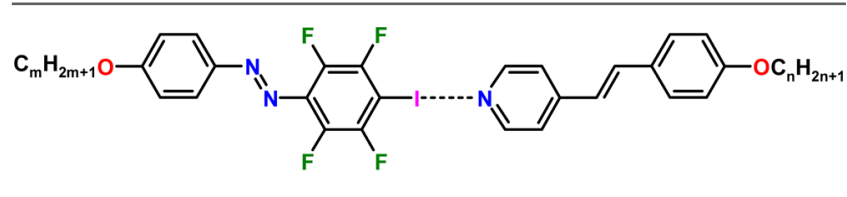

$1-m ; m=8,10,12$

$2-n ; n=1,2,4,8,12$

Figure 1. Studied halogen-bonded photoresponsive LCs 1-m.2-n are formed by self-assembly of the halogen-bond donors $1-\mathrm{m}$ and the acceptor stilbazoles 2-n.

photoactive alkoxyazobenzene molecules 1-m contain an iodo-tetrafluoroarene ring acting as halogen-bond donor moiety, while $4,4^{\prime}$-alkoxystilbazoles 2 -n were used as halogenbond acceptors. Details about the synthesis, characterization, and sample preparation of the $1-\mathrm{m}$ molecules and of their complexes are given in the Experimental Section. Recently, a complex of 2-1 with a halogen-bond-donating azobenzene substituted with a dimethylamino group has been reported to yield interesting photoresponsive behavior. ${ }^{42}$ Herein, we replaced the dimethylamino group of the azobenzene with an alkoxy chain because (i) long alkoxy chains should increase the mesophase stability, compared to the dimethylamino group, and (ii) by decreasing the electron-donating ability of the substituent, the lifetime of the cis-form of the azobenzene should significantly increase. ${ }^{44}$

The photochemical properties of 1-m were first studied in $10^{-5} \mathrm{M}$ DMF solution, and were observed to be identical for all three azobenzenes. Efficient trans-cis isomerization is attested by a decrease of the $\pi-\pi^{*}$ band at $363 \mathrm{~nm}$ and an increase of the $n-\pi^{*}$ band at $436 \mathrm{~nm}$ (Figure 2). The photostationary

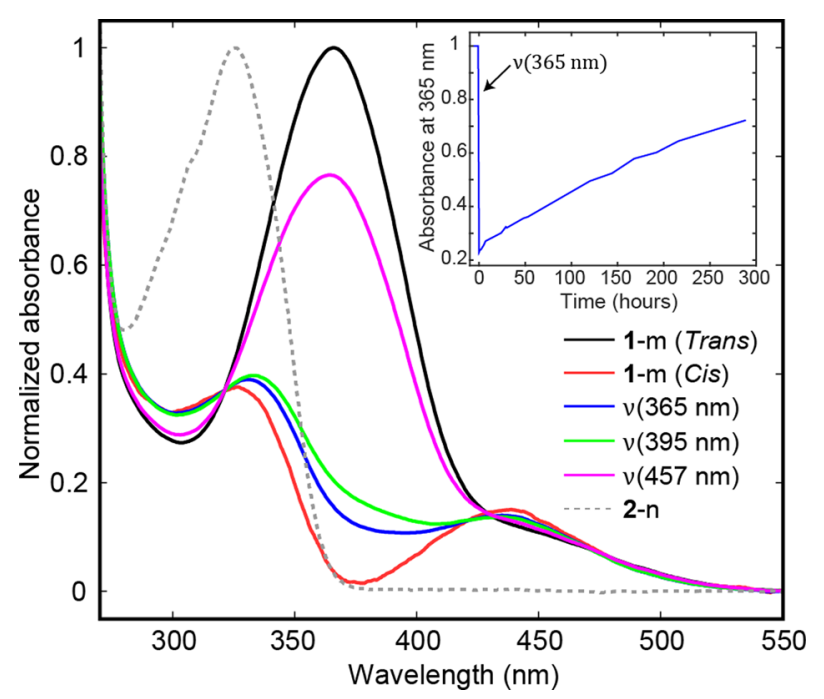

Figure 2. Normalized absorption spectra of the 1-m and 2-n molecules, represented by $1-10$ and 2-2, respectively. The figure shows also the photostationary spectra under illumination wavelengths of 365,395 , and $457 \mathrm{~nm}$, and the calculated spectrum of the cis-isomer for the 1-10 molecule. Inset shows the thermal cis-to-trans isomerization of the molecules at $20{ }^{\circ} \mathrm{C}$ indicating a cis-lifetime of ca. 12 days.

states were deduced by using the Fischer's method, ${ }^{45}$ and they comprised $88 \%, 84 \%$, and $24 \%$ of cis-azobenzenes upon illumination with 365,395 , and $457 \mathrm{~nm}$, respectively. Note that the absorption spectrum of 2-n partly overlaps with that of 1-m (Figure 2), and upon irradiation at $365 \mathrm{~nm}$, the stilbazoles also undergo photoisomerization. Therefore, $395 \mathrm{~nm}$ was the wavelength of choice for this work, yielding efficient isomerization of the azobenzenes while leaving the stilbazoles unchanged. At $20{ }^{\circ} \mathrm{C}$ in DMF, the cis-isomers of the $1-\mathrm{m}$ molecules are highly stable, as illustrated in the inset of Figure 2. The thermal relaxation behavior is exponential, and the characteristic lifetime of the cis-isomer is ca. 12 days for all three molecules, confirming the design assumption (ii) of the previous paragraph. On time scales significantly shorter than the characteristic lifetime, the molecules can be considered to be bistable, which can be attributed to fluorination of the halogen-bond-donating phenyl ring.

The 15 halogen-bonded co-crystals $1-\mathrm{m} \cdot \mathbf{2}$-n were obtained by slow room-temperature evaporation of chloroform solutions containing the starting materials $1-\mathrm{m}$ and $2-n$ in 1:1 molar ratios, which take into account the pairing of the respective strongest halogen-bond donor (I) and acceptor (pyridyl N) sites. $^{33,38} \mathbf{1}-\mathbf{8} \cdot \mathbf{2}-2, \mathbf{1}-\mathbf{1 0} \cdot \mathbf{2}-1$, and $\mathbf{1}-\mathbf{1 2} \cdot \mathbf{2}-1$ were obtained as good-quality single crystals that were analyzed using singlecrystal X-ray diffraction (XRD), with the aim of elucidating the 
supramolecular organization of the starting materials in the cocrystals (see Figure 3, as well as Figures S1-S7 in the Supporting Information).

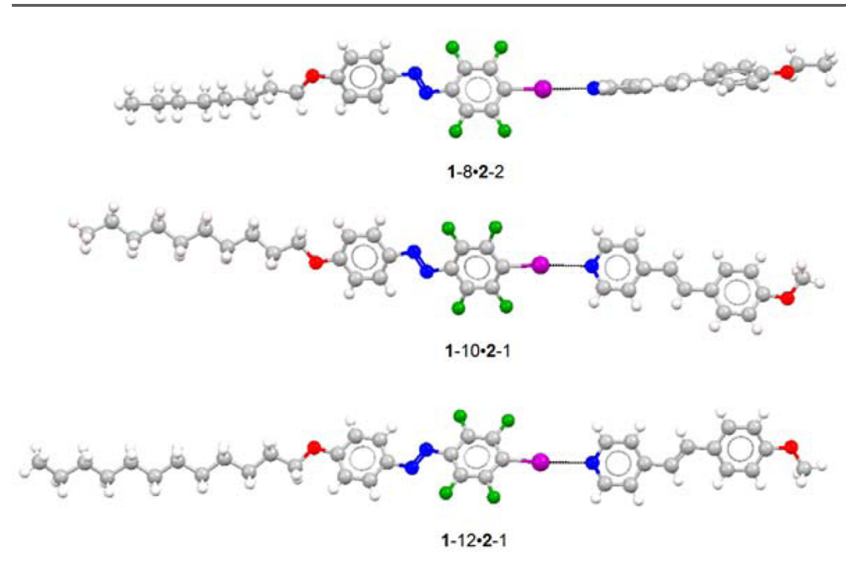

Figure 3. Ball-and-stick representation of the halogen-bonded cocrystals 1-8.2-2, 1-10-2-1, and 1-12-2-1. Strong and directional $\mathrm{I} \cdots \mathrm{N}$ halogen bonds drive the formation of the supramolecular calamitic structures. Color code: gray, $\mathrm{C}$; white, $\mathrm{H}$; red, $\mathrm{O}$; blue, $\mathrm{N}$; green, $\mathrm{F}$; and magenta, I. Halogen bonds are represented by black dotted lines.

1-m and 2-n are assembled into supramolecular dimers by short and highly directional $\mathrm{I} \cdots \mathrm{N}(\mathrm{pyr})$ halogen bonds (see Figure 3$)$. The respective $\mathrm{I} \cdots \mathrm{N}$ distances and $\mathrm{C}-\mathrm{I} \cdots \mathrm{N}$ angles are given as follows: $2.771(2) \AA$ and $178.6^{\circ}$ in $1-8 \cdot 2-2,2.792(1)$ $\AA$ and $174.3^{\circ}$ in $1-10 \cdot 2-1$, and $2.817(2) \AA$ and $174.5^{\circ}$ in $\mathbf{1}-12 \cdot 2$ 1 . The observed halogen-bond distances roughly correspond to a $20 \%$ reduction of the sum of van der Waals radii of I and N. ${ }^{43}$ The strength of such a halogen bond was calculated to be $\sim 6.5$ $\mathrm{kcal} / \mathrm{mol}$ in the reported complexes, which is very consistent with previous calculations. ${ }^{34}$ The high directionality of the halogen bond determines that calamitic structures are obtained, with aromatic rings of the two modules nearly coplanar in 1-10. 2-1 and 1-12-2-1, and orthogonal in 1-8-2-2. The complexes 1 10-2-1 and 1-12-2-1 also exhibit arene-perfluoroarene quadrupolar interactions between neighboring 1-10 and 1-12 molecules in different planes. Because of these quadrupolar interactions, $\mathrm{CH} \cdots \mathrm{O}$ interactions, and $\mathrm{CH} \cdots \pi$ interactions, the halogen-bonded dimers pack head-to-tail in an antiparallel fashion. Residual $\mathrm{CH} \cdots \mathrm{F}$ interactions further stabilize the overall crystal packing. Finally, powder X-ray diffraction (PXRD) analysis (Figures S8-S10 in the Supporting Information) confirmed that the crystalline bulk samples have the same crystal structures, as determined on the analyzed single crystals.

The LC phase behaviors of the complexes were analyzed by hot-stage polarized optical microscopy (POM) and differential scanning calorimetry (DSC). All complexes exhibited enantiotropic LC phases, with the exception of $1-12 \cdot 2-12$, which was monotropic. Nematic phases (Figure 4, left) were common to all complexes, while smectic A (SmA) phases (Figure 4, right) were observed only for complexes with the longest alkyl chains at both ends. We emphasize here that none of the starting compounds is liquid-crystalline as pure material, which implies that the halogen bond between the azobenzene and stilbazole units survives in the mesophase and drives the liquid crystallinity of the supramolecular structures.

The mesomorphism of the halogen-bonded liquid crystals described above is similar to that of analogous stilbazole

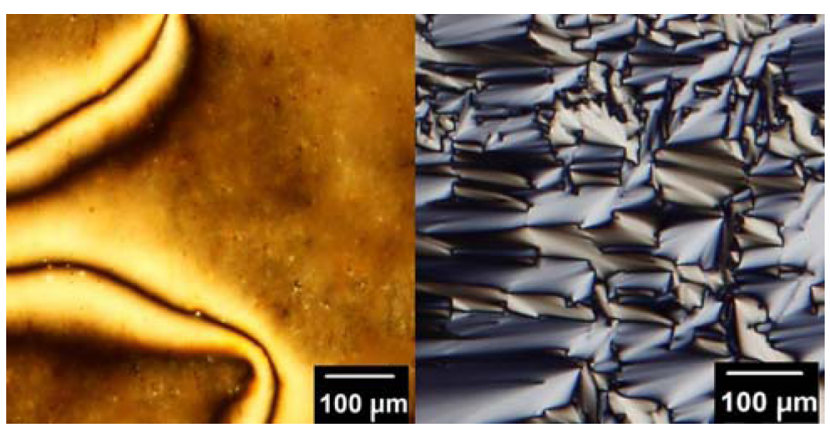

Figure 4. Polarized optical microscopy (POM) micrographs for nematic (left, obtained at $111^{\circ} \mathrm{C}$ ) and smectic A (right, obtained at $107^{\circ} \mathrm{C}$ ) phases in the complex 1-12-2-8.

complexes reported earlier, ${ }^{38}$ showing nematic phases at short chain lengths and SmA phases with longer chains. Apart from the complexes with the shortest chain-length stilbazole, the transition temperatures reveal a destabilization of the nematic phases with increasing $n$ (Figure 5), which is a common

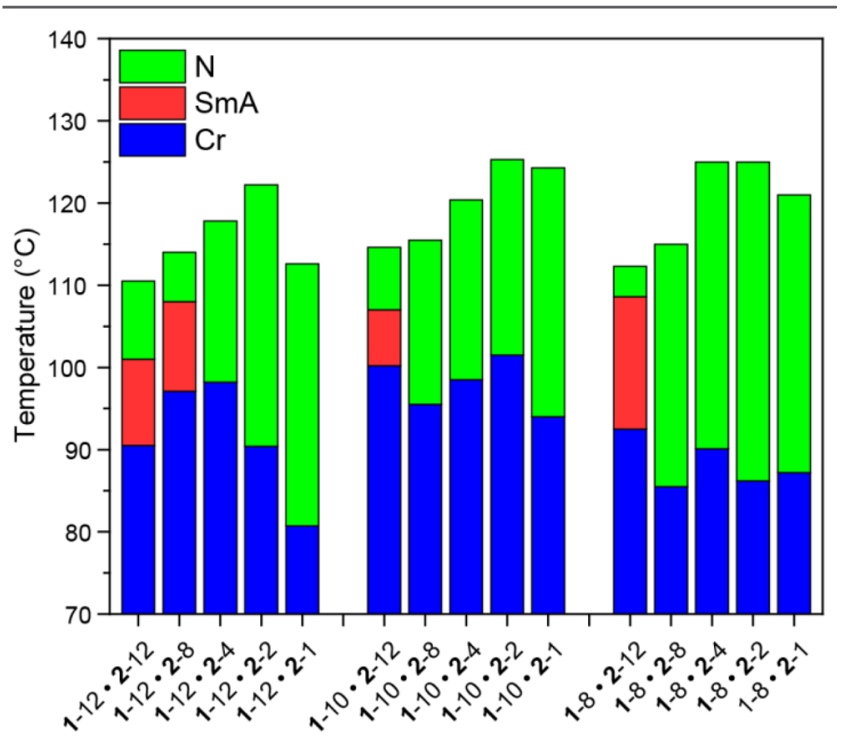

Figure 5. Chart of the thermal behavior of the studied complexes. Color legend: blue, crystal phase; red, SmA phase; and green, N phase. All the transitions are reported upon heating, with the exception of the 1-12-2-12 complex, which was monotropic.

behavior for calamitic mesogens with two terminal chains. A similar picture emerges when considering the variation of the alkoxy chain length on the azobenzene derivatives. Interestingly, the nematic phase extends over a broad temperature range, even exceeding $30{ }^{\circ} \mathrm{C}$ for many of the complexes. By preparing mixtures of several complexes, we were able to further suppress the onset temperatures for the LC phases, compared to single supramolecular entities. For instance, a mixture of 1-12 with 2-2 and 2-12 (in molar ratio of 1.0:0.5:0.5) exhibited a crystal-to-nematic transition at 79.5 ${ }^{\circ} \mathrm{C}$, which is more than $10{ }^{\circ} \mathrm{C}$ lower than that of the pure 1-12. 2-2.

Because of the presence of the azobenzene molecules, the complexes are photoresponsive and undergo a fast and reversible isothermal LC-to-isotropic phase transition upon irradiation with ultraviolet (UV) light $\left(395 \mathrm{~nm}, 40 \mathrm{~mW} / \mathrm{cm}^{2}\right)$. This is illustrated for $1-10 \cdot 2-8$ at $110{ }^{\circ} \mathrm{C}$ in the POM 
micrographs shown in Figure 6, obtained using a planar LC cell with a thickness of $2 \mu \mathrm{m}$. We note that (i) the complex 1-10.2-

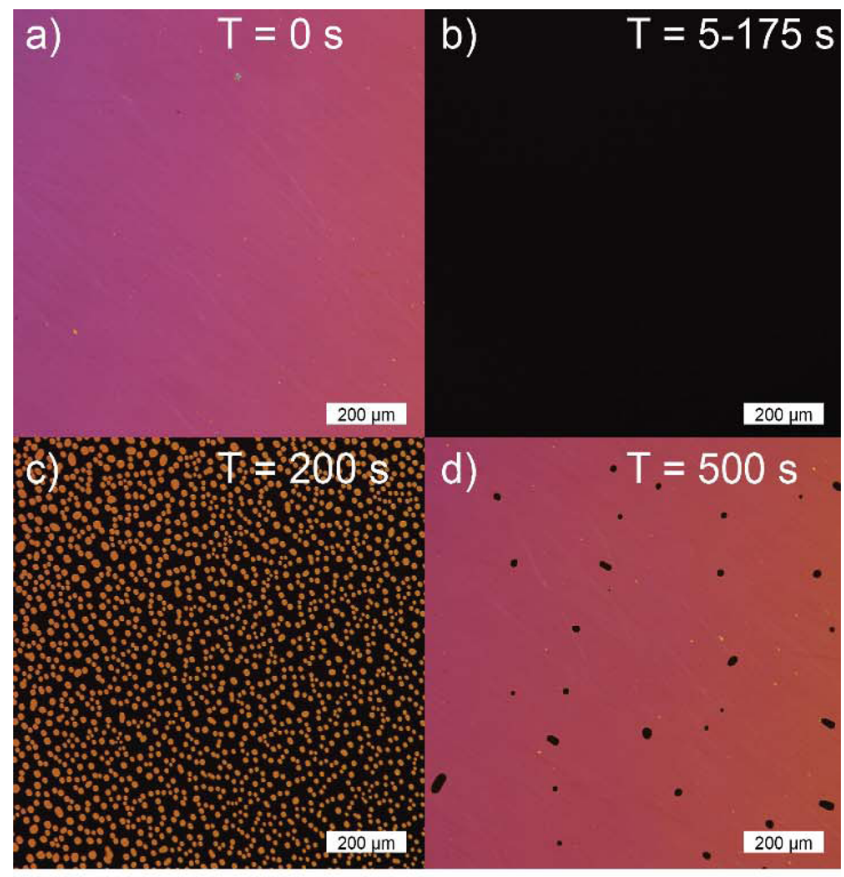

e)

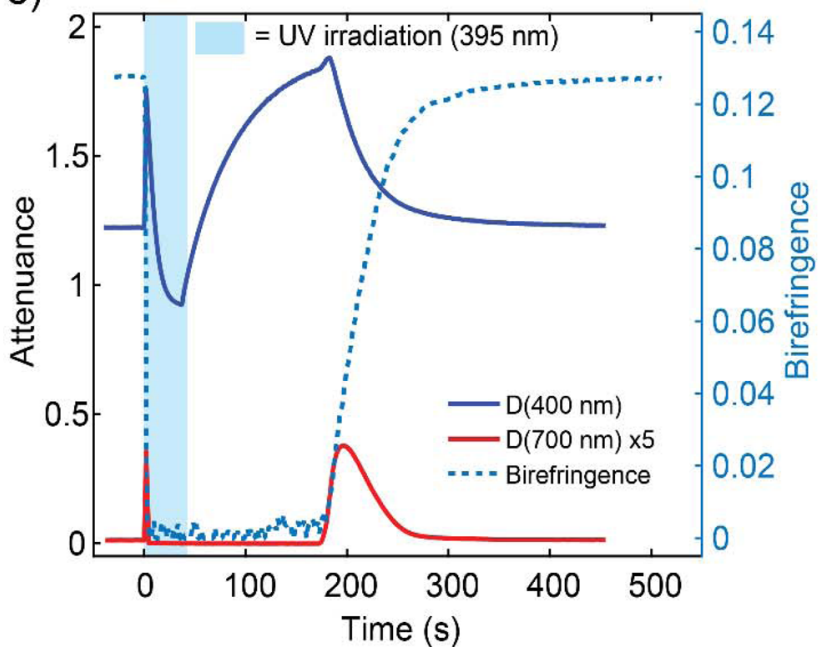

Figure 6. Photoinduced nematic-to-isotropic transition and the reverse transition of 1-10.2-8 observed under POM at $110{ }^{\circ} \mathrm{C}$ : (a) POM image before illumination, (b) POM image after illumination, (c) POM image at the onset of the isotropic-to-nematic transition, and (d) POM image after almost fully reversed transition. (e) Attenuance measurements depicting absorbance $(400 \mathrm{~nm})$ and optical scattering $(700 \mathrm{~nm})$ and birefringence measurements of the photoinduced nematic-to-isotropic transition of $1-10 \cdot 2-8$ at $110{ }^{\circ} \mathrm{C}$.

8 was used as a model system, and (ii) similar behavior is observed also for other complexes and over the entire LC temperature range. Prior to UV irradiation, the sample exhibited a uniformly colored bright image when viewed between crossed polarizers with the director axis set to $\pm 45^{\circ}$, with respect to the polarizer/analyzer (Figure 6a), whereas a black image was obtained when the axes coincided. This indicated homogeneous alignment of the LC complexes. As an example, the order parameter of molecular alignment is 0.44 for the nematic complex $\mathbf{1}-10 \cdot 2-8$ at $105{ }^{\circ} \mathrm{C}$, as determined from polarized absorption spectra. Under illumination, the birefringence due to the anisotropic molecular alignment disappeared within $<3 \mathrm{~s}$ (Figure $6 \mathrm{~b}$ ), indicating the efficient photoinduced phase transition into an isotropic phase. Further illumination, continued in total for $35 \mathrm{~s}$, did not induce further changes into the micrographs. Upon ceasing the illumination, the LC phase reappeared as small domains after a significant delay (Figure $6 c)$, and, with time, the domains recombined and oriented along the rubbing direction (Figure 6d). The small isotropic droplets visible in the bottom right micrograph disappeared upon longer recovery times. We attribute the small LC domains (Figure 6c) as well as the isotropic droplets (Figure 6d) to phase separation between trans-rich liquid-crystalline and cisrich isotropic domains ${ }^{47,48}$ that recombine once the cisazobenzene fraction is sufficiently low.

From the POM images, we can deduce that the complexes exhibit a sequence of different photoinduced processes, and that the LC-to-isotropic phase transition happens relatively fast. In order to further quantify the photochemical processes, we simultaneously monitored the changes in absorbance, birefringence, and optical scattering at different stages of the illumination cycle, as shown in Figure 6e. Such measurements allowed us both to monitor the dynamics of the photoinduced LC-to-isotropic phase transition and to correlate the photoinduced phase separation with the phase transition process. Furthermore, they provided us with an estimate on how much cis-azobenzene is needed to induce phase transitions. To the best of our knowledge, such an effort has not been previously undertaken in supramolecular LCs.

The high birefringence prior to irradiation indicates that the molecules are initially well-oriented, and the decrease in birefringence once the UV illumination is started indicates rapid disappearance of the LC phase, in response to light irradiation. The photoinduced phase transition is accompanied by a rapid increase in both the attenuance at $400 \mathrm{~nm}$ (coinciding with the absorption band of the azobenzene), and attenuance due to optical scattering monitored at $700 \mathrm{~nm}$, where neither of the compounds absorbs. The peak in scattering (the red curve in Figure 6e) indicates that photoinduced phase separation to LC and isotropic domains also occurs upon LC-to-isotropic phase transition. The abrupt increase in the attenuance at $400 \mathrm{~nm}$ once the irradiation is started (the blue curve in Figure 6e) arises from the combination of increased scattering due to phase separation, and changes in the UV-vis absorption spectrum due to a redshift of the $\pi-\pi^{*}$ absorbance band of the azobenzenes, attributed to disrupted molecular packing under UV illumination. The scattering peak disappears within a few seconds, whereas the absorbance at $400 \mathrm{~nm}$ continues to decrease steadily due to trans-cis isomerization for the entire illumination duration, or until the photostationary state is reached. Once the irradiation is ceased (35 s), the absorbance starts to immediately recover as the azobenzene molecules relax back to the thermally stable trans-form. The thermal relaxation is exponential and has a half-life of ca. $51 \mathrm{~s}$ at $110^{\circ} \mathrm{C}$ (while the half-life at room temperature in a dilute DMF solution is $\sim 12$ days). However, there is a significant delay of $\sim 130 \mathrm{~s}$ before the birefringence starts to recover. The onset of birefringence recovery is accompanied by the phase separation process shown in Figure 6c, which, based on the scattering peak, is now significantly slower than upon starting the illumination as it is driven thermally, not by light. 
Based on our observations, there is a clear threshold in the cis-azobenzene concentration that determines the onset of the photoinduced phase transition at a given temperature (Figure S11 in the Supporting Information). By determining the spectra of the trans- and cis-isomers at the isotropic state (a detailed description is given in the Supporting Information (Figures S12 and S13)), the absorbance measurements allowed us to estimate that the onset cis-fraction of azobenzene molecules for the isotropic-to-LC phase transition is $7.6 \% \pm 0.4 \%$. This corresponds to the cis-fraction needed for the full LC-toisotropic transition. Therefore, we can conclude that, similar to azobenzene-doped LCs, ${ }^{22,23}$ the bent shape of the cis-isomer effectively disrupts molecular order also in supramolecular LCs. Considering the 1:1 (azobenzene:stilbazole) nature of the complexes, and the fact that the stilbazole units are not isomerized under the irradiation conditions used, the overall number of cis-isomers needed to achieve the complete LC-toisotropic phase transition is $<4 \%$.

The richness of the photoinduced processes in the complexes under investigation is further highlighted by the fact that, in addition to LC-to-isotropic phase transitions, they also undergo reversible crystal-to-isotropic transitions under irradiation with UV light. Photoresponsive crystalline materials have recently attracted much interest from the viewpoint of energy conversion, actuation, reversible adhesion, and controllable gas adsorption. ${ }^{4-53}$ Photoinduced crystal-to-isotropic transitions have been studied in azobenzene-based tetragonal compounds, ionic crystals, and cyclophanes. ${ }^{54-56}$ However, no such reversible isotropization has been previously reported in supramolecular complexes. Figure 7 a shows a POM image of the complex $1-10 \cdot 2-8$ at $85{ }^{\circ} \mathrm{C}$, i.e., $10{ }^{\circ} \mathrm{C}$ below the melting point and $30{ }^{\circ} \mathrm{C}$ below the clearing point of the complex. Upon illumination $\left(395 \mathrm{~nm}, 40 \mathrm{~mW} / \mathrm{cm}^{2}\right)$, a clear and reversible $\mathrm{Cr}-$

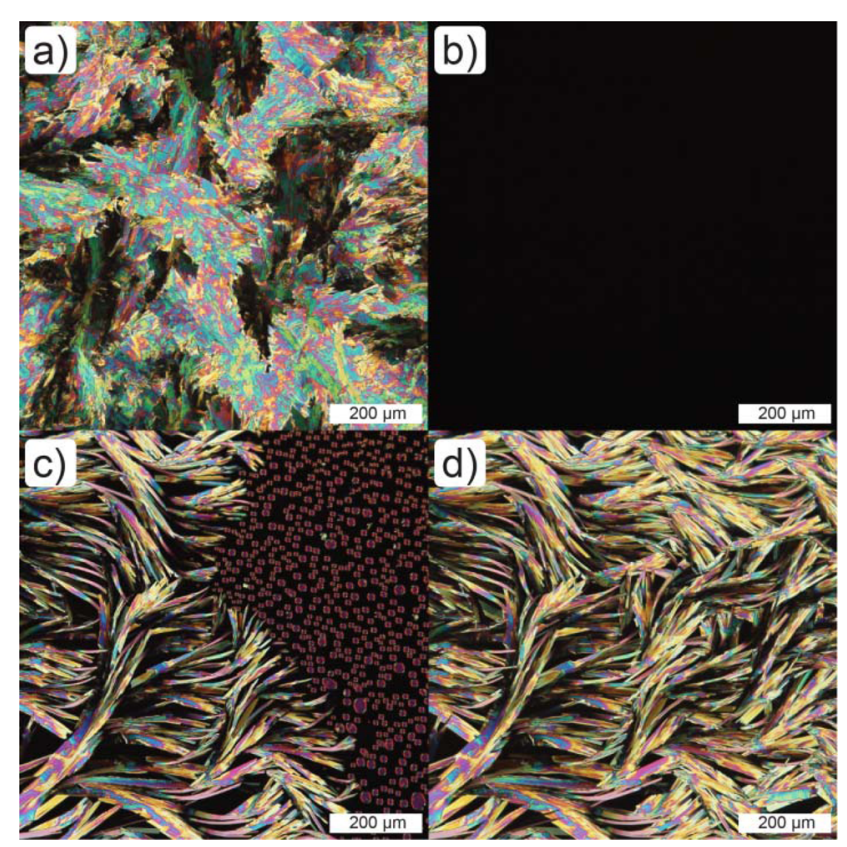

Figure 7. Isotropization of a crystalline sample of 1-10-2-8 upon irradiation with $395 \mathrm{~nm}$ light at $85^{\circ} \mathrm{C}$ : (a) the initial crystals melt into an isotropic liquid; (b) crystals after ca. $30 \mathrm{~s}$ of illumination; (c) recrystallization occurs through a partial nematic phase formation $\sim 3$ min after the illumination was ceased; and (d) the end state is again a fully crystalline material without phase separation.
I transition occurred within $30 \mathrm{~s}$ (Figure $7 \mathrm{~b}$ ). Upon ceasing the irradiation, recrystallization occurred in ca. $3 \mathrm{~min}$, through a partial nematic LC phase (Figure 7c), and the end result was a homogeneous crystalline phase (Figure $7 \mathrm{~d}$ ). The significant delay and the partial nematic phase indicate that the effect is due to photoisomerization rather than a photothermal effect.

\section{CONCLUSIONS}

We have shown that halogen-bond-driven supramolecular liquid crystals (LCs) between alkoxy-substituted azobenzene and stilbazole molecules exhibit a rich variety of photoinduced processes, including photoinduced LC-to-isotropic and crystalto-isotropic phase transitions. Simultaneous analysis of lightinduced changes in birefringence, absorption, and optical scattering allowed us to conclude that $<4 \%$ of the mesogenic units in the cis-form suffices to trigger the full LC-to-isotropic phase transition. To the best of our knowledge, this is the first quantitative analysis of the phase transition process in supramolecular liquid crystals. In our materials design, fluorination plays an important role as it both increases the lifetime of the cis-form of the azobenzene units, and enables the strong and directional halogen bonding to happen. Our future goals are to (i) suppress the temperature at which the complexes exhibit liquid crystallinity, and (ii) devise cholesteric, phototunable LCs driven by halogen bonding. Overall, our results demonstrate the versatility of halogen-bonded complexes as functional liquid-crystalline assemblies and pinpoint their potential toward tunable photonic devices and, eventually, supramolecular actuators.

\section{EXPERIMENTAL SECTION}

The starting materials were purchased from Sigma-Aldrich. Commercial HPLC-grade solvents were used without further purification, except for acetonitrile, which was used as a solvent for the synthesis of azobenzenes, which was dried over $\mathrm{CaH}_{2}$ and distilled prior to use. ${ }^{1} \mathrm{H},{ }^{13} \mathrm{C}$, and ${ }^{19} \mathrm{~F}$ NMR spectra were recorded at room temperature on a Bruker AV400 or AV500 spectrometer, using $\mathrm{CDCl}_{3}$ as the solvent. ${ }^{1} \mathrm{H}$ NMR and ${ }^{13} \mathrm{C}$ NMR spectroscopy chemical shifts were referenced to tetramethylsilane (TMS) using residual proton or carbon impurities of the deuterated solvents as standard references, while ${ }^{19} \mathrm{~F}$ NMR spectroscopy chemical shifts were referenced to an internal $\mathrm{CFCl}_{3}$ standard. The attenuated total reflection Fourier transform infrared (ATR-FTIR) spectra were obtained using a Nicolet Nexus FTIR spectrometer. The values, given in wave numbers, were rounded to $1 \mathrm{~cm}^{-1}$ using automatic peak assignment. Mass spectra were recorded on a Bruker Esquire 3000 PLUS instrument. The LC textures were studied with a Leica DM4500P POM system that was equipped with a Linkam Scientific Model LTS 350 heating stage and a Canon EOS 60D camera. The melting points were also determined on a Reichert instrument by observing the melting process through an optical microscope. DSC analyses were performed on a MettlerToledo DSC823e differential scanning calorimeter, using $40 \mu \mathrm{L}$ aluminum sample pans and Mettler STARe software for calculation.

Photoresponsive Behavior. The photoresponsivity of the halogen-bonded LCs was studied in planar LC cells (E.H.C. Co., Ltd., alignment layer rubbed polyimide) with a thickness of $2 \mu \mathrm{m}$. The temperature was controlled with Linkam Scientific Model LTS 350 heating stage, and the spectra were measured with a Model USB $2000+$ spectrometer (Ocean Optics, Inc.) with nonpolarized light from a deuterium-halogen light source. The samples were illuminated with 365 and $395 \mathrm{~nm}$ high-power LEDs (Thorlabs, Inc.), equipped with 10 $\mathrm{nm}$, OD 4.0, band-pass filters (Edmund Optics, Ltd.), or with a 457 $\mathrm{nm}$ laser. The birefringence $(\Delta n)$ was measured using a $820 \mathrm{~nm}$ laser and crossed polarizers. The sample was placed between the polarizers with a director oriented at angles of $\pm 45^{\circ}$, with respect to the polarizer/analyzer, and the transmitted intensity was measured with a 
photodiode. Using the intensity, the birefringence is then defined as follows:

$$
\frac{I}{I_{0}}=\sin ^{2}\left(\frac{\pi|\Delta n| d}{\lambda}\right)
$$

The order parameter was determined by measuring the polarized absorption spectra with polarizers positioned parallel $\left(A_{\|}\right)$and orthogonal $\left(A_{\perp}\right)$ to the director of the liquid crystal. The order parameter $(S)$ was then calculated by determining the absorbances at $\lambda$ $=420 \mathrm{~nm}$ and using the following equation:

$$
S=\frac{A_{\|}-A_{\perp}}{A_{\|}+2 A_{\perp}}
$$

The characterization of the cis-fraction at the onset of the isotropic-toLC transition (see the Supporting Information for a detailed explanation) is done (i) by determining the trans- and cis-spectra at the isotropic state at $120{ }^{\circ} \mathrm{C}$, and (ii) by assuming the absorbance to be the sum of the trans- and cis-isomers, allowing us to deduce the cisfraction from the absorption spectra at the onset of the isotropic-to-LC transition. In determining the cis-spectrum, the fact that the absorption spectra are different when measured in dilute dimethyl formamide (DMF), in the LC state, and in the isotropic state, must be noted, and also the thermal isomerization must be taken into account. ${ }^{57}$ Because of the thermal isomerization at elevated temperatures (where the samples are isotropic), the photostationary states are measured at different illumination intensities and the photostationary states are extrapolated to infinite irradiation intensities to remove the effect of thermal isomerization. These photostationary spectra are then used, with the help of Fischer's method, ${ }^{45}$ to determine the cis-spectrum. To deduce the cis-fraction at the second stage, the absorbance of the fully trans-state must be determined to be able to use the deduced spectra of trans- and cis-isomers, and this is done by fitting an exponential curve to the time development of the absorbance. With the spectral information on cis- and trans-states deduced by Fischer's method, and knowing the absorbance spectra of the fully trans-state through the exponential fitting, the cis-fraction can be determined from the absorbance measurements.

Synthetic Procedures. Alkoxystilbazoles are well-known premesogens, ${ }^{58}$ while the iodoperfluorinated azobenzenes were prepared by a $\mathrm{NOBF}_{4}$-mediated diazotization reaction between 4-iodo-2,3,5,6tetrafluoroaniline and the relative alkoxybenzene. Reactions were carried out in oven-dried glassware under a nitrogen atmosphere. A solution of 4-iodo-2,3,5,6-tetrafluoroaniline $(3.715 \mathrm{mmol})$ in dry acetonitrile $(5 \mathrm{~mL})$ was added dropwise into a solution of nitrosonium tetrafluoroborate $(3.715 \mathrm{mmol})$ in dry acetonitrile $(5 \mathrm{~mL})$ at $-30{ }^{\circ} \mathrm{C}$. After $1 \mathrm{~h}$ of additional stirring at $-30^{\circ} \mathrm{C}$, a solution of the appropriate alkoxybenzene $(7.43 \mathrm{mmol})$ in dry acetonitrile, was added dropwise. The resulting solution was stirred overnight at room temperature and then water $(15 \mathrm{~mL})$ was added. The mixture was extracted 3-fold with $\mathrm{CH}_{2} \mathrm{Cl}_{2}$. The organic layers were collected and dried over $\mathrm{Na}_{2} \mathrm{SO}_{4}$, and the solvent was removed under reduced pressure. The residue was purified by column chromatography using hexane as eluent to yield the 1 -m molecules $(20 \%-25 \%)$.

1-12. Yield, 25\%; mp, $67{ }^{\circ} \mathrm{C} .{ }^{1} \mathrm{H}$ NMR $\left(500 \mathrm{MHz}, \mathrm{CDCl}_{3}\right): \delta=7.94$ $(\mathrm{d}, J=8 \mathrm{~Hz}, 2 \mathrm{H}), 7.01(\mathrm{~d}, J=8 \mathrm{~Hz}, 2 \mathrm{H}), 4.06(\mathrm{t}, J=6 \mathrm{~Hz}, 2 \mathrm{H}), 1.83$ (quintet, $J=8 \mathrm{~Hz}, 2 \mathrm{H}), 1.48$ (quintet, $J=8 \mathrm{~Hz}, 2 \mathrm{H}), 1.28(\mathrm{~m}, 16 \mathrm{H}$ ), $0.89 \mathrm{ppm}(\mathrm{t}, J=4 \mathrm{~Hz}, 3 \mathrm{H}) ;{ }^{13} \mathrm{C}$ NMR $\left(126 \mathrm{MHz}, \mathrm{CDCl}_{3}\right): \delta=$ $163.68,147.66,147.61\left(\mathrm{ddt},{ }^{1} J_{\mathrm{CF}}=246 \mathrm{~Hz},{ }^{2} J_{\mathrm{CF}}=13 \mathrm{~Hz},{ }^{3} J_{\mathrm{CF}}=5 \mathrm{~Hz}\right)$, $139.90\left(\mathrm{dd},{ }^{1} J_{\mathrm{CF}}=265 \mathrm{~Hz},{ }^{2} J_{\mathrm{CF}}=15 \mathrm{~Hz}\right), 133.32(\mathrm{t}, J=14 \mathrm{~Hz})$, $125.85,115.08,71.60(\mathrm{t}, J=28 \mathrm{~Hz}), 68.76,32.08,29.90-29.65(4 \mathrm{C})$ 29.51 (2C), 29.27, 26.13, 22.84, $14.25 \mathrm{ppm} ;{ }^{19} \mathrm{~F}$ NMR (471 MHz, $\left.\mathrm{CDCl}_{3}\right): \delta=-121.74(\mathrm{~m}, 2 \mathrm{~F}),-150.60 \mathrm{ppm}(\mathrm{m}, 2 \mathrm{~F})$. IR: 2919, 2850, $1599,1578,1472,1407,1252,1143,980,836,587,525 \mathrm{~cm}^{-1}$. MS/ESI $m / z 564.3$, found $587.0\left(\mathrm{M}+\mathrm{Na}^{+}\right)$.

1-10. Yield, 25\%; mp, $68{ }^{\circ} \mathrm{C} .{ }^{1} \mathrm{H}$ NMR $\left(500 \mathrm{MHz}, \mathrm{CDCl}_{3}\right): \delta=7.97$ $(\mathrm{d}, J=8 \mathrm{~Hz}, 2 \mathrm{H}), 7.01(\mathrm{~d}, J=8 \mathrm{~Hz}, 2 \mathrm{H}), 4.06(\mathrm{t}, J=6 \mathrm{~Hz}, 2 \mathrm{H}), 1.83$ (quintet, $J=8 \mathrm{~Hz}, 2 \mathrm{H}), 1.48$ (quintet, $J=8 \mathrm{~Hz}, 2 \mathrm{H}), 1.28(\mathrm{~m}, 12 \mathrm{H}$ ), $0.89 \mathrm{ppm}(\mathrm{t}, J=4 \mathrm{~Hz}, 3 \mathrm{H}) ;{ }^{13} \mathrm{C}$ NMR $\left(126 \mathrm{MHz}, \mathrm{CDCl}_{3}\right): \delta=$
163.69, 147.67, $147.61\left(\mathrm{ddt},{ }^{1} J_{\mathrm{CF}}=246 \mathrm{~Hz},{ }^{2} J_{\mathrm{CF}}=13 \mathrm{~Hz},{ }^{3} J_{\mathrm{CF}}=5 \mathrm{~Hz}\right)$, $139.90\left(\mathrm{dd},{ }^{1} J_{\mathrm{CF}}=265 \mathrm{~Hz},{ }^{2} J_{\mathrm{CF}}=15 \mathrm{~Hz}\right), 133.32(\mathrm{t}, J=14 \mathrm{~Hz})$, $125.86,115.10,71.43(\mathrm{t}, J=28 \mathrm{~Hz}), 68.78,32.05,29.90-29.70(3 \mathrm{C})$, 29.51, 29.27, 26.14, 22.83, $\left.14.24 \mathrm{ppm} ;{ }^{19} \mathrm{~F} \mathrm{NMR} \mathrm{(471} \mathrm{MHz,} \mathrm{CDCl}_{3}\right)$ : $\delta=-121.77(\mathrm{~m}, 2 \mathrm{~F}),-150.65 \mathrm{ppm}$ (m, 2F). IR: 2919, 2850, 1599, $1575,1472,1408,1252,1144,980,858,587,525 \mathrm{~cm}^{-1}$. MS/ESI $\mathrm{m} / z$ 536.2, found $559.0\left(\mathrm{M}+\mathrm{Na}^{+}\right)$.

1-8. Yield, 20\%; mp, $72{ }^{\circ} \mathrm{C} .{ }^{1} \mathrm{H} \mathrm{NMR}\left(500 \mathrm{MHz}, \mathrm{CDCl}_{3}\right): \delta=7.94$ (d, $J=8 \mathrm{~Hz}, 2 \mathrm{H}), 7.01(\mathrm{~d}, J=8 \mathrm{~Hz}, 2 \mathrm{H}), 4.06(\mathrm{t}, J=6 \mathrm{~Hz}, 2 \mathrm{H}), 1.83$ (quintet, $J=8 \mathrm{~Hz}, 2 \mathrm{H}$ ), 1.48 (quintet, $J=8 \mathrm{~Hz}, 2 \mathrm{H}), 1.30(\mathrm{~m}, 8 \mathrm{H})$, $0.90 \mathrm{ppm}(\mathrm{t}, J=4 \mathrm{~Hz}, 3 \mathrm{H}) ;{ }^{13} \mathrm{C}$ NMR $\left(126 \mathrm{MHz}, \mathrm{CDCl}_{3}\right): \delta=$ $163.68,147.66,147.61\left(\mathrm{ddt},{ }^{1} J_{\mathrm{CF}}=246 \mathrm{~Hz},{ }^{2} J_{\mathrm{CF}}=14 \mathrm{~Hz},{ }^{3} J_{\mathrm{CF}}=5 \mathrm{~Hz}\right)$, $139.90\left(\mathrm{dd},{ }^{1} J_{\mathrm{CF}}=265 \mathrm{~Hz},{ }^{2} J_{\mathrm{CF}}=15 \mathrm{~Hz}\right), 133.32(\mathrm{t}, J=13 \mathrm{~Hz})$, $125.81,114.99,71.67(\mathrm{t}, J=28 \mathrm{~Hz}), 68.69,31.95,29.74,29.48,29.24$, 26.12, 22.81, $14.25 \mathrm{ppm} ;{ }^{19} \mathrm{~F}$ NMR (471 MHz, $\left.\mathrm{CDCl}_{3}\right): \delta=-121.75$ (m, 2F), -150.66 ppm (m, 2F). IR: 2924, 2855, 1601, 1578, 1474, $1408,1245,1146,979,849,567,531 \mathrm{~cm}^{-1}$. MS/ESI $\mathrm{m} / z$ 508.2, found $530.9\left(\mathrm{M}+\mathrm{Na}^{+}\right)$.

X-ray Diffraction. The azobenzene derivatives and the stilbazoles were separately dissolved in $\mathrm{CHCl}_{3}$ at room temperature in 1:1 ratio, under saturated conditions. The two saturated solutions containing the halogen-bond donor and the halogen-bond acceptor were then mixed in a clear borosilicate glass vial, which was left open. The solvent was allowed to slowly evaporate at room temperature for 3 days until the formation of good-quality single crystals occurred $(1-10 \cdot 2-1,1-12 \cdot 2-1$, and 1-8.2-2).

Single-crystal XRD data were collected on a Bruker AXS KAPPAAPEX II CCD diffractometer using Mo K $\alpha$ radiation $(\lambda=0.71073 \AA)$ equipped with Bruker KRYOFLEX low-temperature device. Data integration and reduction were performed using SaintPlus 6.01. ${ }^{59}$ Absorption correction was performed with a multiscan method implemented in SADABS. ${ }^{60,61}$ Space groups were determined using XPREP implemented in APEX II suite. ${ }^{62}$ Structures were solved using SHELXS-97 (direct methods) and refined using SHELXL-2008 ${ }^{63}$ (full-matrix least-squares on $F^{2}$ ) contained in APEX II and WinGX v1.80.01 software packages. ${ }^{64}$ All non-hydrogen atoms were refined anisotropically. Hydrogen atoms were placed in geometrically calculated positions and included in the refinement process using a riding model with isotropic thermal parameters. Analysis of crystal data and figures were performed with Mercury 3.5.1.2. ${ }^{65}$ Crystal data are reported in Table S1 in the Supporting Information.

PXRD data were collected on a Bruker AXS D8 powder diffractometer was used for all measurements with experimental parameters as follows: $\mathrm{Cu} \mathrm{K} \alpha$ radiation $(\lambda=1.54056 \AA)$; scanning interval, $5^{\circ}-30^{\circ} 2 \theta$; step size, $0.016^{\circ}$; and exposure time, $1.5 \mathrm{~s} / \mathrm{step}$. Small shifts in $2 \theta$ values between the powder patterns of the simulated from single crystal and the experimental XRD spectra are due to different acquisition temperatures. Single crystal structures were collected at 103 or $150 \mathrm{~K}$, while bulk powder materials were recorded at $298 \mathrm{~K}$.

Computational Analysis. All geometry minimizations were performed with the M06-2X/def2-TZVP method, using Gaussian 09, Revision D.01. ${ }^{66}$ The complexation energy between 2-1 and 1-1 was further obtained with a single-point energy calculation employing the full counter-poise method to correct for the basis set superposition error. An ultrafine grid was used in all calculations. Default values were used for other parameters. The optimized geometry is given in Figure S14 in the Supporting Information.

\section{ASSOCIATED CONTENT}

\section{S Supporting Information}

The Supporting Information is available free of charge on the ACS Publications website at DOI: 10.1021/acs.chemmater.6b03460.

Crystallographic data, (tables, additional pictures, and CIF), powder X-ray data, quantitative analysis of the photoinduced phase transitions, thermal data, computed atomic coordinates (PDF) 


\section{AUTHOR INFORMATION}

\section{Corresponding Authors}

*E-mail: marco.saccone@tut.fi.

*E-mail: pierangelo.metrangolo@polimi.it.

*E-mail: arri.priimagi@tut.fi.

\section{Author Contributions}

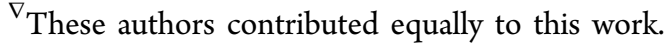

\section{Notes}

The authors declare no competing financial interest.

\section{ACKNOWLEDGMENTS}

P.M. is grateful to the European Research Council (ERC) for funding the Starting Grant FOLDHALO (Grant Agreement No. 307108). The Academy of Finland's Centres of Excellence Programme (2014-2019) is also acknowledged. A.P. greatly acknowledges the ERC Starting Grant program (Grant Agreement No. 679646), the Academy of Finland Research Fellowship program (Decision Nos. 277091 and 284553), and the Emil Aaltonen Foundation for financial support.

\section{REFERENCES}

(1) Lehn, J.-M. Perspectives in Chemistry-Steps towards Complex Matter. Angew. Chem., Int. Ed. 2013, 52, 2836-2850.

(2) Sun, H.-J.; Zhang, S.; Percec, V. From Structure to Function via Complex Supramolecular Dendrimer Systems. Chem. Soc. Rev. 2015, 44, 3900-3923.

(3) Lagerwall, J. P. F.; Scalia, G. A New Era for Liquid Crystal Research: Applications of Liquid Crystals in Soft Matter Nano-, Bioand Microtechnology. Curr. Appl. Phys. 2012, 12, 1387-1412.

(4) Tschierske, C. Development of Structural Complexity by LiquidCrystal Self-Assembly. Angew. Chem., Int. Ed. 2013, 52, 8828-8878.

(5) Yu, H.; Ikeda, T. Photocontrollable Liquid-Crystalline Actuators. Adv. Mater. 2011, 23, 2149-2180.

(6) Liu, D.; Broer, D. J. Liquid Crystal Polymer Networks: Preparation, Properties, and Applications of Films with Patterned Molecular Alignment. Langmuir 2014, 30, 13499-13509.

(7) Lee, K. M.; Wang, D. H.; Koerner, H.; Vaia, R. A.; Tan, L.-S.; White, T. J. Enhancement of Photogenerated Mechanical Force in Azobenzene-Functionalized Polyimides. Angew. Chem., Int. Ed. 2012, 51, 4117-4121.

(8) De Sio, L.; Tabiryan, N.; Bunning, T.; Kimball, B. R.; Umeton, C. Dynamic Photonic Materials Based on Liquid Crystals. Prog. Opt. 2013, 58, 1-64.

(9) Liu, D.; Broer, D. J. New Insights into Photoactivated Volume Generation Boost Surface Morphing in Liquid Crystal Coatings. Nat. Commun. 2015, 6, 8334.

(10) Liu, D.; Liu, L.; Onck, P. R.; Broer, D. J. Reverse Switching of Surface Roughness in a Self-Organized Polydomain Liquid Crystal Coating. Proc. Natl. Acad. Sci. U. S. A. 2015, 112, 3880-3885.

(11) Iamsaard, S.; Anger, E.; Aßhoff, S. J.; Depauw, A.; Fletcher, S. P.; Katsonis, N. Fluorinated Azobenzenes for Shape-Persistent Liquid Crystal Polymer Networks. Angew. Chem., Int. Ed. 2016, 55, 99089912.

(12) Min Lee, K.; Lynch, B. M.; Luchette, P.; White, T. J. Photomechanical Effects in Liquid Crystal Polymer Networks Prepared with M -Fluoroazobenzene. J. Polym. Sci., Part A: Polym. Chem. 2014, 52, 876-882.

(13) Kumar, K.; Knie, C.; Bléger, D.; Peletier, M. A.; Friedrich, H.; Hecht, S.; Broer, D. J.; Debije, M. G.; Schenning, A. P. H. J. A Chaotic Self-Oscillating Sunlight-Driven Polymer Actuator. Nat. Commun. 2016, 7, 11975.

(14) Beharry, A. A.; Sadovski, O.; Woolley, G. A. Azobenzene Photoswitching without Ultraviolet Light. J. Am. Chem. Soc. 2011, 133, 19684-19687.

(15) Bléger, D.; Schwarz, J.; Brouwer, A. M.; Hecht, S. oFluoroazobenzenes as Readily Synthesized Photoswitches Offering
Nearly Quantitative Two-Way Isomerization with Visible Light. J. Am. Chem. Soc. 2012, 134, 20597-20600.

(16) Knie, C.; Utecht, M.; Zhao, F.; Kulla, H.; Kovalenko, S.; Brouwer, A. M.; Saalfrank, P.; Hecht, S.; Bléger, D. OrthoFluoroazobenzenes: Visible Light Switches with Very Long-Lived Z Isomers. Chem. - Eur. J. 2014, 20, 16492-16501.

(17) Weston, C. E.; Richardson, R. D.; Haycock, P. R.; White, A. J. P.; Fuchter, M. J. Arylazopyrazoles: Azoheteroarene Photoswitches Offering Quantitative Isomerization and Long Thermal Half-Lives. J. Am. Chem. Soc. 2014, 136, 11878-11881.

(18) Hird, M. Fluorinated Liquid Crystals - Properties and Applications. Chem. Soc. Rev. 2007, 36, 2070-2095.

(19) Tschierske, C. Fluorinated Liquid Crystals: Design of Soft Nanostructures and Increased Complexity of Self-Assembly by Perfluorinated Segments. Top. Curr. Chem. 2011, 318, 1-108.

(20) Kato, T.; Mizoshita, N.; Kanie, K. Hydrogen-Bonded Liquid Crystalline Materials: Supramolecular Polymeric Assembly and the Induction of Dynamic Function. Macromol. Rapid Commun. 2001, 22, $797-814$.

(21) Paleos, C. M.; Tsiourvas, D. Supramolecular Hydrogen-Bonded Liquid Crystals. Liq. Cryst. 2001, 28, 1127-1161.

(22) Legge, C. H.; Mitchell, G. R. Photo-Induced Phase Transitions in Azobenzene-Doped Liquid Crystals. J. Phys. D: Appl. Phys. 1992, 25, 492-499.

(23) Sung, J.-H.; Hirano, S.; Tsutsumi, O.; Kanazawa, A.; Shiono, T.; Ikeda, T. Dynamics of Photochemical Phase Transition of Guest/Host Liquid Crystals with an Azobenzene Derivative as a Photoresponsive Chromophore. Chem. Mater. 2002, 14, 385-391.

(24) Shishido, A.; Tsutsumi, O.; Kanazawa, A.; Shiono, T.; Ikeda, T.; Tamai, N. Rapid Optical Switching by Means of Photoinduced Change in Refractive Index of Azobenzene Liquid Crystals Detected by Reflection-Mode Analysis. J. Am. Chem. Soc. 1997, 119, 7791-7796.

(25) Desiraju, G. R.; Ho, P. S.; Kloo, L.; Legon, A. C.; Marquardt, R.; Metrangolo, P.; Politzer, P.; Resnati, G.; Rissanen, K. Definition of the Halogen Bond (IUPAC Recommendations 2013). Pure Appl. Chem. 2013, 85, 1711-1713.

(26) Legon, A. C. Prereactive Complexes of Dihalogens XY with Lewis Bases B in the Gas Phase: A Systematic Case for the Halogen Analogue $\mathrm{B} \cdots \mathrm{XY}$ of the Hydrogen Bond B $\cdots \mathrm{HX}$. Angew. Chem., Int. Ed. 1999, 38, 2686-2714.

(27) Shields, Z. P.; Murray, J. S.; Politzer, P. Directional Tendencies of Halogen and Hydrogen Bonds. Int. J. Quantum Chem. 2010, 110, 2823-2832.

(28) Cavallo, G.; Metrangolo, P.; Milani, R.; Pilati, T.; Priimagi, A.; Resnati, G.; Terraneo, G. The Halogen Bond. Chem. Rev. 2016, 116, $2478-2601$.

(29) Priimagi, A.; Cavallo, G.; Metrangolo, P.; Resnati, G. The Halogen Bond in the Design of Functional Supramolecular Materials: Recent Advances. Acc. Chem. Res. 2013, 46, 2686-2695.

(30) Berger, G.; Soubhye, J.; Meyer, F. Halogen Bonding in Polymer Science: From Crystal Engineering to Functional Supramolecular Polymers and Materials. Polym. Chem. 2015, 6, 3559-3580.

(31) Bushuyev, O. S.; Corkery, T. C.; Barrett, C. J.; Friščić, T. PhotoMechanical Azobenzene Cocrystals and in Situ X-Ray Diffraction Monitoring of Their Optically-Induced Crystal-to-Crystal Isomerisation. Chem. Sci. 2014, 5, 3158-3164.

(32) Bushuyev, O. S.; Tomberg, A.; Vinden, J. R.; Moitessier, N.;

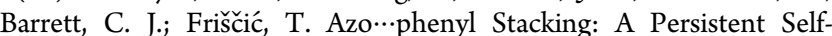
Assembly Motif Guides the Assembly of Fluorinated Cis-Azobenzenes into Photo-Mechanical Needle Crystals. Chem. Commun. 2016, 52, 2103-2106.

(33) Fox, D.; Metrangolo, P.; Pasini, D.; Pilati, T.; Resnati, G.; Terraneo, G. Site-Selective Supramolecular Synthesis of HalogenBonded Cocrystals Incorporating the Photoactive Azo Group. CrystEngComm 2008, 10, 1132-1136.

(34) Saccone, M.; Dichiarante, V.; Forni, A.; Goulet-Hanssens, A.; Cavallo, G.; Vapaavuori, J.; Terraneo, G.; Barrett, C. J.; Resnati, G.; Metrangolo, P.; Priimagi, A. Supramolecular Hierarchy among 
Halogen and Hydrogen Bond Donors in Light-Induced Surface Patterning. J. Mater. Chem. C 2015, 3, 759-768.

(35) Vapaavuori, J.; Heikkinen, I. T. S.; Dichiarante, V.; Resnati, G.; Metrangolo, P.; Sabat, R. G.; Bazuin, C. G.; Priimagi, A.; Pellerin, C. Photomechanical Energy Transfer to Photopassive Polymers through Hydrogen and Halogen Bonds. Macromolecules 2015, 48, 7535-7542.

(36) Nguyen, H. L.; Horton, P. N.; Hursthouse, M. B.; Legon, A. C.; Bruce, D. W. Halogen Bonding: A New Interaction for Liquid Crystal Formation. J. Am. Chem. Soc. 2004, 126, 16-17.

(37) Bruce, D. W.; Metrangolo, P.; Meyer, F.; Präsang, C.; Resnati, G.; Terraneo, G.; Whitwood, A. C. Mesogenic, Trimeric, HalogenBonded Complexes from Alkoxystilbazoles and 1,4-Diiodotetrafluorobenzene. New J. Chem. 2008, 32, 477-482.

(38) Bruce, D. W.; Metrangolo, P.; Meyer, F.; Pilati, T.; Präsang, C.; Resnati, G.; Terraneo, G.; Wainwright, S. G.; Whitwood, A. C. Structure-Function Relationships in Liquid-Crystalline HalogenBonded Complexes. Chem. - Eur. J. 2010, 16, 9511-9524.

(39) González, L.; Gimeno, N.; Tejedor, R. M.; Polo, V.; Ros, M. B.; Uriel, S.; Serrano, J. L. Halogen-Bonding Complexes Based on Bis(iodoethynyl)benzene Units: A New Versatile Route to Supramolecular Materials. Chem. Mater. 2013, 25, 4503-4510.

(40) Cavallo, G.; Terraneo, G.; Monfredini, A.; Saccone, M.; Priimagi, A.; Pilati, T.; Resnati, G.; Metrangolo, P.; Bruce, D. W. Superfluorinated Ionic Liquid Crystals Based on Supramolecular, Halogen-Bonded Anions. Angew. Chem., Int. Ed. 2016, 55, 6300-6304.

(41) Xu, J.; Liu, X.; Ng, J. K.-P.; Lin, T.; He, C. Trimeric Supramolecular Liquid Crystals Induced by Halogen Bonds. J. Mater. Chem. 2006, 16, 3540-3545.

(42) Priimagi, A.; Saccone, M.; Cavallo, G.; Shishido, A.; Pilati, T.; Metrangolo, P.; Resnati, G. Photoalignment and Surface-ReliefGrating Formation Are Efficiently Combined in Low-MolecularWeight Halogen-Bonded Complexes. Adv. Mater. 2012, 24, OP345OP352.

(43) Chen, Y.; Yu, H.; Zhang, L.; Yang, H.; Lu, Y. Photoresponsive Liquid Crystals Based on Halogen Bonding of Azopyridines. Chem. Commun. 2014, 50, 9647-9649.

(44) Bandara, H. M. D.; Burdette, S. C. Photoisomerization in Different Classes of Azobenzene. Chem. Soc. Rev. 2012, 41, 18091825.

(45) Fischer, E. Calculation of Photostationary States in Systems A $\rightleftharpoons$ B When Only A Is Known. J. Phys. Chem. 1967, 71, 3704-3706.

(46) Bondi, A. Van Der Waals Volumes and Radii. J. Phys. Chem. 1964, 68, 441-451.

(47) Tong, X.; Wang, G.; Zhao, Y. Photochemical Phase Transition versus Photochemical Phase Separation. J. Am. Chem. Soc. 2006, 128, $8746-8747$.

(48) Tong, X.; Zhao, Y. Multiple Photochemical Processes in Liquid Crystalline Azo Dye-Doped Liquid Crystals. Chem. Mater. 2009, 21, 4047-4054.

(49) Morimoto, M.; Irie, M. A Diarylethene Cocrystal That Converts Light into Mechanical Work. J. Am. Chem. Soc. 2010, 132, 1417214178.

(50) Kim, T.; Zhu, L.; Al-Kaysi, R. O.; Bardeen, C. J. Organic Photomechanical Materials. ChemPhysChem 2014, 15, 400-414.

(51) Kucharski, T. J.; Ferralis, N.; Kolpak, A. M.; Zheng, J. O.; Nocera, D. G.; Grossman, J. C. Templated Assembly of Photoswitches Significantly Increases the Energy-Storage Capacity of Solar Thermal Fuels. Nat. Chem. 2014, 6, 441-447.

(52) Naumov, P.; Sahoo, S. C.; Zakharov, B. A.; Boldyreva, E. V. Dynamic Single Crystals: Kinematic Analysis of Photoinduced Crystal Jumping (The Photosalient Effect). Angew. Chem., Int. Ed. 2013, 52, 9990-9995.

(53) Bushuyev, O. S.; Tomberg, A.; Friščić, T.; Barrett, C. J. Shaping Crystals with Light: Crystal-to-Crystal Isomerization and Photomechanical Effect in Fluorinated Azobenzenes. J. Am. Chem. Soc. 2013, $135,12556-12559$.

(54) Baroncini, M.; d'Agostino, S.; Bergamini, G.; Ceroni, P.; Comotti, A.; Sozzani, P.; Bassanetti, I.; Grepioni, F.; Hernandez, T. M.; Silvi, S.; Venturi, M.; Credi, A. Photoinduced Reversible Switching of Porosity in Molecular Crystals Based on Star-Shaped Azobenzene Tetramers. Nat. Chem. 2015, 7, 634-640.

(55) Hoshino, M.; Uchida, E.; Norikane, Y.; Azumi, R.; Nozawa, S.; Tomita, A.; Sato, T.; Adachi, S.; Koshihara, S. Crystal Melting by Light: X-Ray Crystal Structure Analysis of an Azo Crystal Showing Photoinduced Crystal-Melt Transition. J. Am. Chem. Soc. 2014, 136, 9158-9164.

(56) Ishiba, K.; Morikawa, M.; Chikara, C.; Yamada, T.; Iwase, K.; Kawakita, M.; Kimizuka, N. Photoliquefiable Ionic Crystals: A Phase Crossover Approach for Photon Energy Storage Materials with Functional Multiplicity. Angew. Chem., Int. Ed. 2015, 54, 1532-1536.

(57) Rau, H.; Greiner, G.; Gauglitz, G.; Meier, H. Photochemical Quantum Yields in the $\mathrm{A}(+\mathrm{h} \nu) \rightleftarrows \mathrm{B}(+\mathrm{h} \nu, \Delta)$ System When Only the Spectrum of A Is Known. J. Phys. Chem. 1990, 94, 6523-6524.

(58) Bruce, D. W.; Dunmur, D. A.; Lalinde, E.; Maitlis, P. M.; Styring, P. 4-Alkyloxy-4'-stilbazoles New Heterocyclic Mesogens. Liq. Cryst. 1988, 3, 385-395.

(59) Saint Plus, v.6.01; Bruker Analytical X-Ray Systems: Madison, WI, 1999.

(60) Sheldrick, G. M. SADABS: Empirical Absorption Correction Program; University of Gottingen, Germany, 2001. (Based on the Method of Blessing.)

(61) Blessing, R. H. An Empirical Correction for Absorption Anisotropy. Acta Crystallogr., Sect. A: Found. Crystallogr. 1995, 51, 33-38.

(62) APEXII v2009. Version 5-1; Bruker Analytical X-Ray Systems: Madison, WI, 2009.

(63) Sheldrick, G. M. A Short History of SHELX. Acta Crystallogr., Sect. A: Found. Crystallogr. 2008, 64, 112-122.

(64) Farrugia, L. J. WinGX Suite for Small-Molecule Single-Crystal Crystallography. J. Appl. Crystallogr. 1999, 32, 837-838.

(65) Macrae, C. F.; Edgington, P. R.; McCabe, P.; Pidcock, E.; Shields, G. P.; Taylor, R.; Towler, M.; van de Streek, J. Mercury: Visualization and Analysis of Crystal Structures. J. Appl. Crystallogr. 2006, 39, 453-457.

(66) Frisch, M. J.; Trucks, G. W.; Schlegel, H. B.; Scuseria, G. E.; Robb, M. A.; Cheeseman, J. R.; Scalmani, G.; Barone, V.; Mennucci, B.; Petersson, G. A.; Nakatsuji, H.; Caricato, M.; Li, X.; Hratchian, H. P.; Izmaylov, A. F.; Bloino, J.; Zheng, G.; Sonnenberg, J. L.; Hada, M.; Ehara, M.; Toyota, K.; Fukuda, R.; Hasegawa, J.; Ishida, M.; Nakajima, T.; Honda, Y.; Kitao, O.; Nakai, H.; Vreven, T.; Montgomery, J. A., Jr.; Peralta, J. E.; Ogliaro, F.; Bearpark, M.; Heyd, J. J.; Brothers, E.; Kudin, K. N.; Staroverov, V. N.; Kobayashi, R.; Normand, J.; Raghavachari, K.; Rendell, A.; Burant, J. C.; Iyengar, S. S.; Tomasi, J.; Cossi, M.; Rega, N.; Millam, J. M.; Klene, M.; Knox, J. E.; Cross, J. B.; Bakken, V.; Adamo, C.; Jaramillo, J.; Gomperts, R.; Stratmann, R. E.; Yazyev, O.; Austin, A. J.; Cammi, R.; Pomelli, C.; Ochterski, J. W.; Martin, R. L.; Morokuma, K.; Zakrzewski, V. G.; Voth, G. A.; Salvador, P.; Dannenberg, J. J.; Dapprich, S.; Daniels, A. D.; Farkas, Ö.; Foresman, J. B.; Ortiz, J. V.; Cioslowski, J.; Fox, D. J. Gaussian 09, Revision D.01; Gaussian, Inc.: Wallingford, CT, 2009. 